\title{
Influence of therapeutic ultrasound on the biomechanical characteristics of the skin
}

\author{
Lígia Brancalion Catapani ${ }^{1}$, Adriana da Costa Gonçalves ${ }^{2}$, Nathalia Morano Candeloro ${ }^{1}$, Lídia Aparecida Rossi ${ }^{3}$ \\ and Elaine Caldeira de Oliveira Guirro ${ }^{1,2^{*}}$
}

\begin{abstract}
Background: Skin function is dependent on its biomechanical characteristics, resistance, malleability, and elasticity. Therapeutic ultrasound may increase cutaneous malleability thus and optimize the rehabilitation process on specific diseases. The aim of this study is to evaluate possible alterations of biomechanical characteristics of the normal skin after therapeutic ultrasound application.

Methods: Thirty-one volunteers took part of the study, and the average age was $31.61 \pm 8.37$ years old. Biomechanical characteristics evaluation of the skin was performed with the Cutometer MPA 580 (Courage + Khazaka Electronic —Köln, Germany) of 2-mm probe hole and 500-mbar vacuum. Skin characteristics were analyzed before and after therapeutic ultrasound application, and the variables R0 (distensibility), R2 (gross elasticity), and R6 (viscoelasticity) were used for the study. Areas of therapeutic ultrasound application (continuous, $3 \mathrm{MHz}, 1 \mathrm{~W} / \mathrm{cm}^{2}$ SATA) were defined at the upper limbs and standardized using a neoprene template. Sociodemographic data of volunteers were analyzed using SPSS 15.0. To analyze the distribution of the data, the Shapiro-Wilk test was used, which showed the normal distribution for Ro values, R2 and R6. For this procedure, the PROC TTEST from SAS ${ }^{\circledR} 9.0$ software and Minitab 16 software, with significance, was set at the 0.05 level.
\end{abstract}

Results: In relation to RO, a significant increase ( $p=0.001)$ was observed for the distensibility, when compared to values of pre- $(0.3273 \mathrm{~mm})$ and immediately post- $(0.3795 \mathrm{~mm})$ resource application which feature a greater distensibility. Related to R2 values, a significant increase $(p=.001)$ of the gross elasticity at pre- $(0.8419)$ and post- $(0.8884)$ therapeutic ultrasound application was found.

Conclusions: Therapeutic ultrasound promotes significant alterations of the biomechanical characteristics of the skin.

Trial registration: ClinicalTrials.gov, 1111-1146-7342

Keywords: Skin, Elasticity, Therapeutic ultrasound

Abbreviations: BMI, Body mass index; Mm, Millimeters; US, Ultrasound

\section{Background}

The skin, the largest organ in the human body, performs multiple functions [1], including mechanical effects on tissue elasticity [2], a characteristic that is responsible for the return of the skin to its original form

\footnotetext{
* Correspondence: ecguirro@fmrp.usp.br

'Department of Biomechanics, Medicine and Rehabilitation of the Locomotor System, Ribeirão Preto Medical School, University of São Paulo, Ribeirão Preto, São Paulo, Brazil

${ }^{2}$ Postgraduation Program in Rehabilitation and Functional Performance, University of São Paulo, 3900 Bandeirantes Avenue, 14049-900 Ribeirão Preto, São Paulo, Brazil

Full list of author information is available at the end of the article
}

after tension removal [3]. It may vary according to the age, evaluated tissue composition, among others [4].

Biomechanical characteristics of tissues have been widely used as a characterization of these important since many pathological and physiological changes involving tissue. Properties such as elasticity, viscoelasticity, and distensibility which can be evaluated objectively are essential for the detection of skin disorders [5-7].

Ultrasonic energy is frequently used in soft tissue treatment, which causes therapeutic responses related to thermal and non-thermal (mechanical) effects [8-11].

The therapeutic ultrasound induces physiological changes in the skin [12], and this may lead to alterations 
of the extensibility of tissues through modifications in collagen properties by the thermal effects of therapeutic ultrasound [13-15].

Thermal ultrasound effect can be effective in increasing extensibility of collagen, thus aiding joint mobilization and stretching $[11,16]$.

The therapeutic ultrasound physical parameters that are best able to increase tissue malleability, especially skin malleability, remain to be established. There is a discrepancy related to the effects of therapeutic ultrasound at the collagen tissue extensibility between in vivo and in vitro studies [17], after the therapeutic ultrasound application. No studies were found that evaluate the influence of ultrasound on biomechanical characteristics of normal skin. The present study aims to elucidate the biological effects induced by therapeutic ultrasound on the skin and support the therapeutic intervention in tissue dysfunction.

\section{Methods}

\section{Sample}

Thirty-one volunteers took part of the study; the average age was $31.61( \pm 8.37)$ years old, from both genders. Subjects who presented comorbidities or deformities that could affect the skin structure and function were excluded from the study.

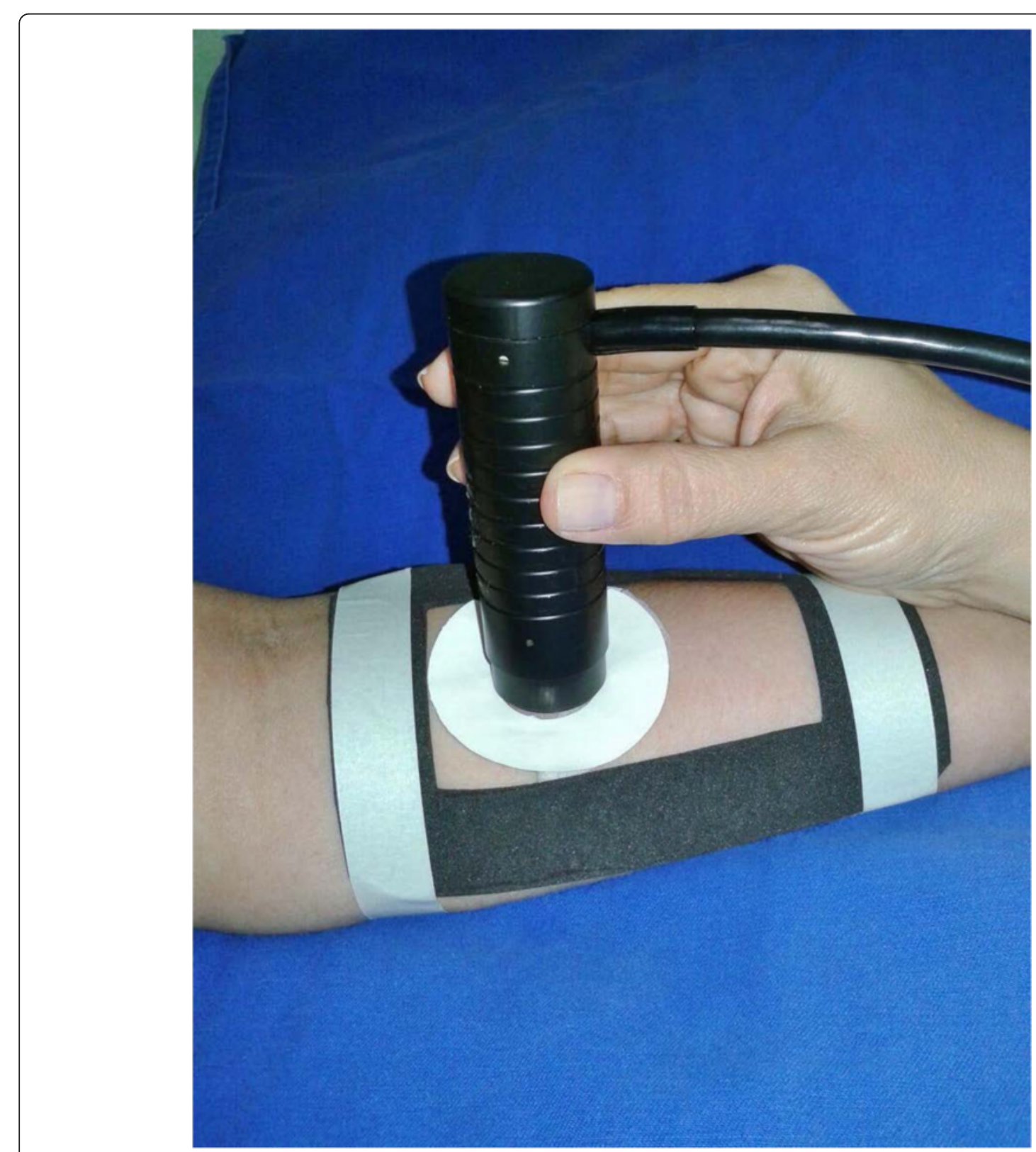

Fig. 1 Cutometer probe application with specific adhesive rings fixed in the anterior forearm and delimited by a neoprene template 


\section{Instrumentation}

Evaluation of biomechanical characteristics of the skin was performed by the Cutometer, model MPA 580 (Courage + Khazaka Electronic-Köln, Germany), a probe of 2-mm hole and 500 mbar of suction per second, before and after the therapeutic procedure. The Cutometer is a noninvasive tool that facilitates analysis and characterization of the functional state of the skin, as well as the measurement of responses initiated by different therapeutic resources [5, 6, 18-22].

The evaluated zone was standardized and limited by a neoprene template of the $9 \times 5 \mathrm{~cm}$ area, cut at precisely two times the size of the effective radiating area of the ultrasound applicator onto the skin, and this served to restrict all treatments to the same size surface area $[15,23]$. The areas established for evaluations with Cutometer bounded by specific adhesive rings for this purpose, positioned at the top edge of the mold to ensure the standardized location of the adhesives, removed for therapeutic interventions with the resources, and repositioned following (Fig. 1).

Measurements were performed after 20-min resting, controlled environment (temperature between 20 and $25{ }^{\circ} \mathrm{C}$ and humidity ranging 30-50 \%), always in the morning in

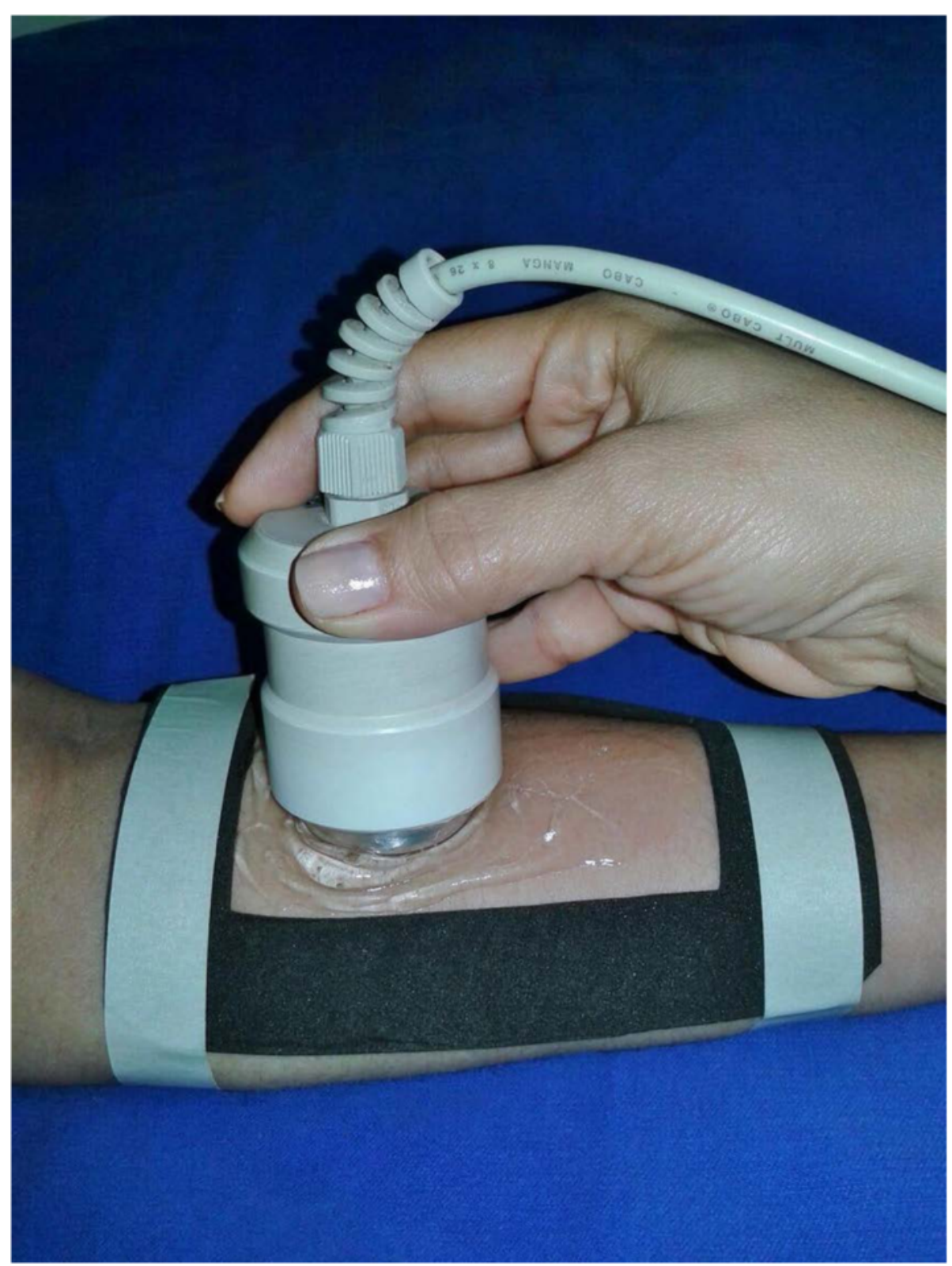

Fig. 2 Application of therapeutic ultrasound in delimited area with neoprene template 
order to avoid interference in the chronobiological characteristics of the skin [24], and all assessments made in the anterior forearm because of the biomechanical characteristics of the skin vary in different regions [25]. The probe was maintained at the delimited area by $6 \mathrm{~s}, 500$ mbar of suction, three times repetition, normalization of temperature interval, performed $15 \mathrm{~min}$ after skin contact [26], with representative displacement curves calculated by the Cutometer software [27-29].

The therapeutic intervention was performed with ultrasound Sonopulse III (IBRAMED-Amparo, Brazil) and it was periodically submitted to calibrations (irradiation pressure scale Ohmic UPMDT 10 model) [30]. The following parameters were employed: continuous mode, 3$\mathrm{MHz}$ frequency, and $1 \mathrm{~W} / \mathrm{cm}^{2}$ (SATA) intensity at the selected area and gel was used as a coupling agent. Irradiation time was 2 min per ERA (effective radiating area) of the transductor at both sides of the upper limbs, in a total of 4 min of application at a delimited area (Fig. 2).

Biomechanical characteristics analysis of the skin were performed in sequence and variables observed were the following: R0 - distensibility; R2 - gross elasticity (resistance against return capability of the tissue), which values close to one indicate greater elasticity, and R6 - viscoelasticity for which lower values indicate greater elasticity [31].

\section{Statistical analyses}

Sociodemographic data of volunteers were analyzed using SPSS 15.0 (percentage, average with standard deviation, and median with minimum and maximum value).

To analyze the distribution of the data, the ShapiroWilk test was used, which showed the normal distribution for R0 values, R2 and R6. For this procedure, the PROC TTEST from SAS ${ }^{ø} 9.0$ software was used in contribution to the Minitab 16 Software. Statistical significance was set at 0.05 level.

\section{Results}

Sociodemographic features of the volunteers $(n=31)$ were the following: $31.61( \pm 8.37)$ years, the main gender was male (61.3\%, 19), youthful adult, $51.4 \%$ (18) Caucasians, presenting the mean body mass index (BMI) of 25.44. From 31 upper limb areas evaluated, $22(70.96 \%)$ were arms, 6 (19.35\%) were forearms, and $3(9.67 \%)$ were the back of the hand.

Regarding biomechanical features of the skin pre- and post-therapeutic ultrasound (US) application, for R0 (distensibility, absolute value in $\mathrm{mm}$ ), a significant increase of tissue distensibility could be noticed after therapeutic ultrasound application and the same was observed for R2 (gross elasticity, relative value) and R6 (viscoelasticity, relative value), being data respectively reported in Tables 1, 2, and 3.
Table 1 Values of the Ro variable before and after therapeutic ultrasound application at normal skin

\begin{tabular}{lccll}
\hline Variable R0 & Number & $\begin{array}{l}\text { Average } \\
(\mathrm{mm})\end{array}$ & $\begin{array}{l}\text { Standard } \\
\text { deviation }(\mathrm{mm})\end{array}$ & $\begin{array}{l}\text { Standard error } \\
(\mathrm{mm})\end{array}$ \\
\hline Pre-intervention & 31 & 0.3273 & 0.1038 & 0.0186 \\
Post-intervention & 31 & $0.3795^{*}$ & 0.1042 & 0.0187 \\
Difference & & -0.05226 & 0.05396 & 0.00969 \\
\hline
\end{tabular}

*Differs from pre- $(p=0.001)$

Table 1 and Fig. 3 demonstrate $95 \%$ significance level, with difference showed by values of R0 pre- and posttherapeutic ultrasound, considering $p=0.001$ for the statistic test of $t$ value $=-5.39$, with a reliability interval difference average $(-0.07205 ;-0.03246)$.

Regarding to R2, relative value (Table 2) and Fig. 4, it is also possible to notice that for the same significance level of $95 \%$, there is evidence that R2 values before are different from those post-therapeutic ultrasound application, considering $p=0.001$ for statistic test of $t$ value $=3.83$, with a reliability interval difference average $(-0.0712 ;-0.0216)$.

The R6 variable indicated in Table 3 and Fig. 5, where it is considered $p=0.001$ for a statistic $t$ value test $=6.57$ and a reliability interval of $95 \%$ for difference in averages of 0.0672 and 0.1279 , did not present significant deviations of normality.

\section{Discussion}

No previous study has investigated the effect of therapeutic ultrasound (US) on biomechanical characteristics (distensibility, elasticity, and viscoelasticity) of the skin.

The effects inherent to the increase of malleability by therapeutic ultrasound are related to heating that is intensity-dependent, as well as to quantity of collagen fibers at the tissue submitted for treatment, whereupon the greater collagen quantity, the better is the absorption [23], with better efficiency at continuous mode [32].

Despite the ultrasound often be used in therapeutic procedures, inefficiencies highlighted in the results are probably due to wrong parameters, not considering the size of the area, duration, intensity, frequency, type of fabric, transducer movement, and the therapeutic window [16]. The present study utilized an application time of 4 min which was used in a bound area of approximately $10 \mathrm{~cm}^{2}$.

Table 2 Values of the R2 variable before and after therapeutic ultrasound application at normal skin

\begin{tabular}{lllll}
\hline Variable R2 & Number & Average & $\begin{array}{l}\text { Standard } \\
\text { deviation }\end{array}$ & $\begin{array}{l}\text { Standard } \\
\text { error }\end{array}$ \\
\hline Pre-intervention & 31 & 0.8419 & 0.0946 & 0.0170 \\
Post-intervention & 31 & $0.8884^{*}$ & 0.0624 & 0.0112 \\
Difference & & -0.0464 & 0.0675 & 0.0121
\end{tabular}

${ }^{*}$ Differs from pre- $(p=0.001)$ 
Table 3 Values of the R6 variable before and after therapeutic ultrasound application at normal skin

\begin{tabular}{lllll}
\hline Variable R6 & Number & Average & $\begin{array}{l}\text { Standard } \\
\text { deviation }\end{array}$ & $\begin{array}{l}\text { Standard } \\
\text { error }\end{array}$ \\
\hline Pre-intervention & 31 & 0.4605 & 0.1079 & 0.0194 \\
Post-intervention & 31 & $0.3629^{*}$ & 0.0934 & 0.0168 \\
Difference & & 0.0976 & 0.0827 & 0.0149 \\
\hline
\end{tabular}

*Differs from pre- $(p=0.001)$

The absorption of ultrasound in tissues is determined by the protein constituents, being observed enhanced absorption in the tissue with more collagen [33], and skin dermis fibers are responsible for providing elasticity and also resistance to lengthening [34, 35].

Body segments set out for elasticity evaluation of the skin were the forearm, arm, and back of the hand which are considered easily accessible areas and relatively flat [36], optimizing the procedures performed. Measurements of biomechanical features of the skin were always done by the same observer, so it would be possible to standardize pressure at the probe; different pressures at the probe of Cutometer may produce different responses [31, 36-38].

The utilization of Cutometer equipment has been described previously, as an important and effective tool for objective and non-invasive measurements of biomechanical properties of the skin, yielding absolute and relative data. A study has used the Cutometer to evaluate the elasticity of the skin related to age, while the other has analyzed the skin elasticity in different parts of the body, and both studies found differences, which is the reason why it has been standardized to specific areas and age for evaluation $[39,40]$.

For the World Health Organization [41], a body mass index (BMI) lower than 18.5 indicates low weight; ranging between 18.5 and 24.9 indicates a normal weight and higher than 25 is considered overweight. In the present study, the average of the body mass index of volunteers fits in the overweight. However, there is controversy regarding correlations of skin elasticity and obesity rate.

The study [42] did not find a correlation between skin elasticity and obesity degree. However, Smalls [4] demonstrates a potential influence of body composition at biomechanical properties of the skin, the reason why those values were evaluated.

Other authors [43] have pointed that a single observer can safely utilize the Cutometer for measuring skin elasticity, as well as reported that R0 (Ue) may be used in an adequate way for measuring, assuming that it is one of the best variables to quantify skin elasticity, being $\mathrm{R} 0$ measurement related by authors [44] to plastic and elastic deformations.

Because lower values of R0 represent greater firmness, i.e., lower skin distensibility, it is possible to notice a significant increase of this tissue property after therapeutic ultrasound application at normal skin in the present study, even as observing the R2 variable, which has also demonstrated greater elasticity, proving the efficacy of therapeutic ultrasound reported on literature regarding to the increase of distensibility [42].

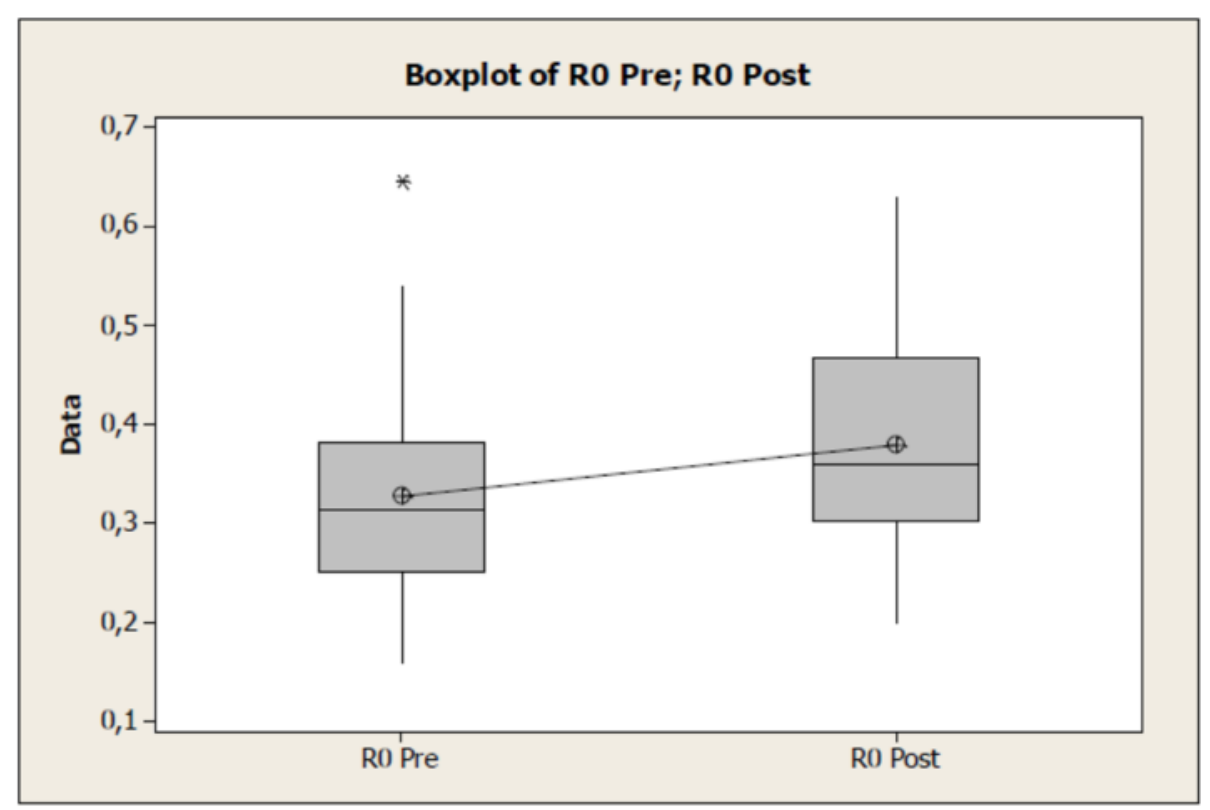

Fig. 3 Values of the RO (mm) variable before and after therapeutic ultrasound application on normal skin 


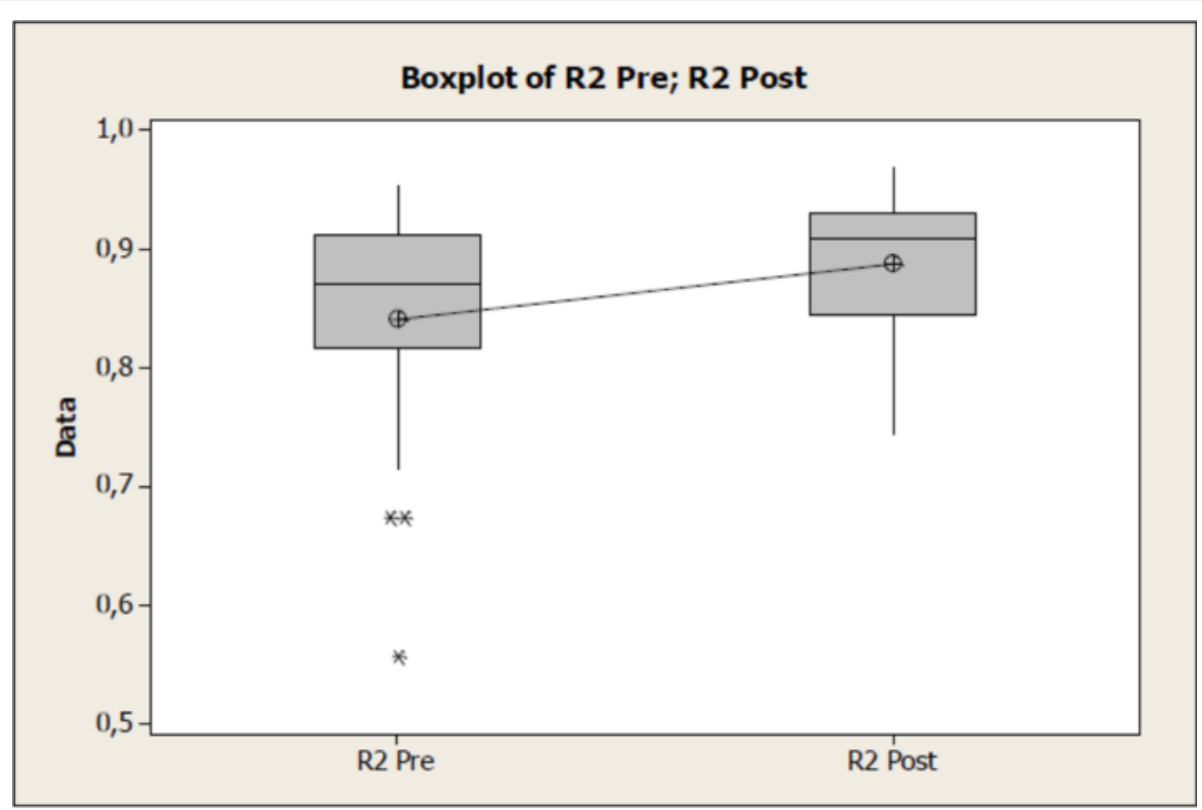

Fig. 4 Values of the R2 variable before and after therapeutic ultrasound application on normal skin

When skin elasticity resistance (Ue) is at the limit, sustained strength applied to the skin results in a greater deformation on it due to viscoelasticity (Uv) which moves the interstitial fluid through skin fibrous net [27]. The viscoelasticity represented by this variable showed a significant decrease of its initial average value. Considering that the lower the R6 value, the greater the elasticity, it is possible to notice an improvement of elasticity at normal skin after therapeutic ultrasound application, corroborating to the findings of authors who study the effects of therapeutic ultrasound regarding the increase of tissue elasticity [45].

The Cutometer can also be used to evaluate biomechanical properties of morbidities of the skin, such as burns and keloids. The anisotropic behavior of different tissues relative to the normal skin should be considered in the studies [46-48].

Feature-inherent effects of therapeutic ultrasound at the skin may guide studies that evaluate the effect of therapeutic resources at different morbidities.

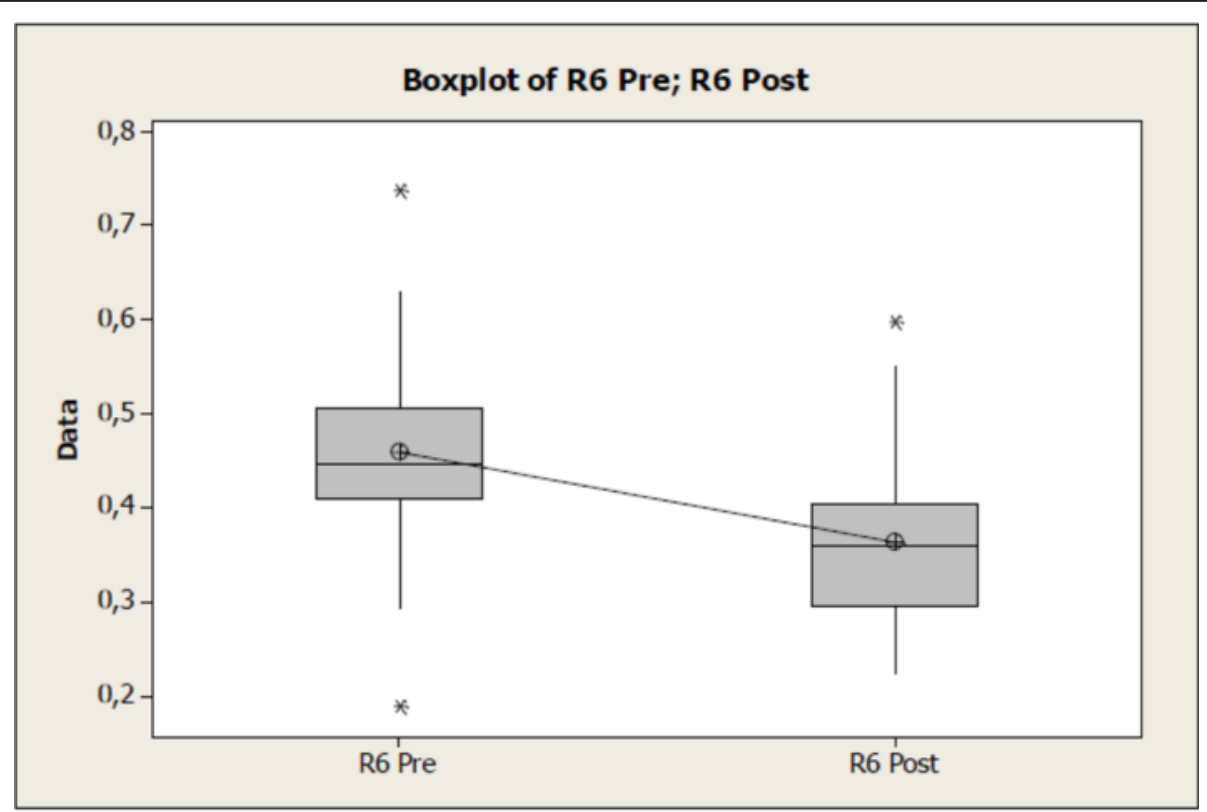

Fig. 5 Values of the R6 variable before and after therapeutic ultrasound application on normal skin 
The results of this study are limited to effects produced by a single application of therapeutic ultrasound. The assessment of the effects produced by chronic treatment can clarify the effects inherent to stimulation with the largest number of interventions with therapeutic ultrasound.

\section{Conclusions}

Significant alterations on the biomechanical characteristics of the normal skin after therapeutic ultrasound application were found.

The effects of therapeutic resources on the different tissues are still a challenge to researchers; increased knowledge about the effects in different tissues is important in the treatment of different clinical conditions.

\section{Acknowledgements}

The authors acknowledge the contributions of the Institutional Program of Research Fellowships/Rectory of the University of São Paulo (PIBIC/RUSP), the State of São Paulo Research Foundation (FAPESP), and the National Council for Scientific and Technological Development (CNPq) which sponsored this study

\section{Funding}

Funding was provided by the state of São Paulo Research Foundation (FAPESP), ref. 2010/10006-8, and the National Council for Scientific and Technological Development (CNPq), ref. 472467/2011-5.

\section{Availability of data and materials}

The datasets obtained during and/or analyzed during the current study are available from the corresponding author on reasonable request.

\section{Authors' contributions}

LBC and ACG analyzed and drafted the manuscript. NC interpreted the data. EOCG provided the study design and prepared the manuscript. LAR carried out the collaboration of observed variable interpretation. All authors have read and approved the final manuscript.

\section{Competing interests}

The authors declare that they have no competing interests.

\section{Consent for publication}

We have obtained the written informed consent to publish of all participants.

\section{Ethics approval and consent to participate}

The ethical committee (at the University of São Paulo) approved the study, protocol number 13386/2011. All participants signed the consent forms.

\section{Author details}

${ }^{1}$ Department of Biomechanics, Medicine and Rehabilitation of the Locomotor System, Ribeirão Preto Medical School, University of São Paulo, Ribeirão Preto, São Paulo, Brazil. ${ }^{2}$ Postgraduation Program in Rehabilitation and Functional Performance, University of São Paulo, 3900 Bandeirantes Avenue, 14049-900 Ribeirão Preto, São Paulo, Brazil. ${ }^{3}$ Ribeirão Preto College of Nursing, University of São Paulo, Ribeirão Preto, Brazil.

Received: 30 September 2015 Accepted: 10 August 2016 Published online: 17 August 2016

\section{References}

1. Firooz A, Sadr B, Babakoohi S, Yazdy SM, Fanian F, Timsar KA, Kashani NM, Naghizadeh MM, Dowlati Y. Variation of biophysical parameters of the skin with age, gender, and body region. Scient World J. 2012;2012:1-5.

2. Luebberding S, Krueger N, Kerscher M. Mechanical properties of human skin in vivo: a comparative evaluation in 300 men and women. Skin Res Technol. 2014;20:127-35.
3. Brusselaers N, Pirirayesh A, Hoeksema H, Verbelen J, Blot S, Monstrey S. Burn scar assessment: a systematic review of different scar scales. J Surg Res. 2010;164:115-23.

4. Smalls LK, Randall WR, Visscher MO. Effect of dermal thickness, tissue composition, and body site on skin biomechanical properties. Skin Res Technol. 2006;12:43-9.

5. Ambroisine L, Ezzedine K, Elfakir A, Gardinier S, Latreille J, Mauger E, et al. Relationships between visual and tactile features and biophysical parameters in human facial skin. Skin Res Technol. 2007;13:176-83.

6. Reuther T, Bayrhammer J, Kerscher M. Use of biophysical techniques to evaluate the physiologic effects of injected hyaluronic acid. Hautarzt. 2007; 12(58):1046-50.

7. Liang X, Stephen A, Boppart SA. Biomechanical properties of in vivo human skin from dynamic optical coherence elastography. IEEE Trans Biomed Eng. 2010;57(4):953-9.

8. Chen YW, Tzeng Jl, Huang PC, Hung CH, Shao DZ, Wang Jl. Therapeutic ultrasound suppresses neuropathic pain and upregulation of substance $\mathrm{p}$ and neurokinin-1 receptor in rats after peripheral nerve injury. Ultrasound Med Biol. 2015;41:143-50.

9. De Bem DM, Maciel CD, Zuanon JA, Neto CB, Parizotto NA. Histological analysis of healthy epithelial tissue of Wistar rats (in vivo) irradiated with different ultrasound intensities. Braz J Phys Ther. 2010;14:114-20.

10. Emsen IM. The effect of ultrasound on flap survival: an experimental study in rats. Burns. 2007;33:369-71.

11. Rose S, Draper DO, Schulthies SS, Durrant E. The stretching window part two: rate of thermal decay in deep muscle following 1-MHz ultrasound. J Athletic Training. 1996;31:139-43.

12. Olsson DC, Martins VMV, Martin SE, Mazzanti A. Pulsed and continuous ultrasound stimulation in rats healing celiotomy. Cienc Rural. 2006;36:865-72.

13. Morishita K, Karasuno H, Yokoi Y, Morozumi K, Ogihara H, Ito T. Effects of therapeutic ultrasound on range of motion and stretch pain. J Phys Ther Sci. 2014;26:711-5.

14. Blanco MGR, Bencivenga MJ, Jensen LG. Effectiveness of $3 \mathrm{MHz}$ ultrasound in pediatric patients with scars, sequels of 2nd to 3rd degree burns. Plastic Surgery Rehabilitation Area of Children Hospital, Cordoba, Argentina: 20062012. Rev Bras Queimaduras. 2013:12:77-82.

15. Draper DO, Ricard MD. Rate of temperature decay in human muscle following $3 \mathrm{MHz}$ ultrasound: the stretching window revealed. J Athletic Training. 1995;30:304-7.

16. Draper DO. Facts and misfits in ultrasound therapy: steps to improve your treatment outcomes. Eur J Phys Rehabil Med. 2014;50:209-16.

17. Boucaud A, Montharu J, Machet L, Arbeille B, Machet MC, Patat F, et al. Clinical, histologic and electron microscopy study of skin exposed to lowfrequency ultrasound. Anat Rec. 2001;264(1):114-9.

18. Sadick NS, Harth Y. A 12-week clinical and instrumental study evaluating the efficacy of a multisource radiofrequency home use device for wrinkle reduction and improvement is skin tone, skin elasticity, and dermal collagen content. J Cosmet Laser Ther. 2016;28:1-26.

19. Kerscher M, Bayrhammer J, Reuther T. Rejuvenating influence of a stabilized hyaluronic acid-based gel of nonanimal origin on facial skin aging. Dermatol Surg. 2008;34(5):720-6.

20. Lodén M. Biophysical methods of providing objective documentation of the effects of moisturizing creams. Skin Res Technol. 2006;3:101-8.

21. Rennekampff HO, Rabels J, Reinhard V. Comparing the Vancouver Scar Scale with the cutometer in the assessment of donor site wounds treated with various dressings in a randomized trial. J Burn Car Res. 2006;27:345-51.

22. Egawa M, Oguri M, Hirao T, Takahashi M, Miyakawa M. The evaluation of skin friction using a frictional feel analyzer. Skin Res Technol. 2002;8:41-51.

23. Nishimori Y, Edwards C, Pearse A, et al. Degenerative alterations of dermal collagen fiber bundles in photodamaged human skin and UV-irradiated hairless mouse skin: possible effect on decreasing skin mechanical properties and appearance of wrinkles. J Inv Dermatol. 2001;117:1458-63.

24. Tsukahara K, Takema Y, Moriwaki S, Fujimura T, Imokawa G. Dermal fluid translocation is an important determinant of the diurnal variation in human skin thickness. British J Dermatol. 2001;145(4):590-6.

25. Ryu HS, Joo YH, Kim SO, Park KC, Youn SW. Influence of age and regional differences on skin elasticity as measured by the cutometer. Skin Res Technol. 2008;14(3):354-8.

26. Magalhães MF, Dibai-Filho AV, et al. Evolution of skin temperature after the application of compressive forces on tendon, muscle and myofascial trigger point. PLoS One. 2015;10(6):e0129034. 
27. Bonaparte JP, Ellis D. Alterations in the elasticity, pliability and viscoelastic properties of facial skin after injection of onabotulinum toxin a. Jama Facial Plast Surg. 2015;17:256-63.

28. Held M, Rothenberger J, Schiefer J, Rath R, Petersen W, Jaminet P, Rahmanian-Schwarz A. Alteration of biomechanical properties of skin in acute cold contact injury. Burns. 2014;40:1384-9.

29. Woo MS, Moon KJ, Jung HY, Park SR, Moon TK, Kim NS, Lee BC. Comparison of skin elasticity test results from the Ballistometer ${ }^{\oplus}$ and Cutometer ${ }^{\oplus}$. Skin Res Technol. 2014;20:422-8.

30. Ferrari $C B$, Andrade MA, Adamowski JC, Guirro RRJ. Evaluation of therapeutic ultrasound equipment performance. Ultrasonics. 2010;50(7):704-9.

31. Bonaparte JP, Ellis D, Chung J. The effect of probe to skin contact force on Cutometer MPA 580 measurements. J Med Eng Technol. 2013;37:208-12.

32. Baker KG, Robertson VJ, Duck FA. A review of therapeutic ultrasound: biophysical effects. Phys Ther. 2001:81:1351-8.

33. Watson T. Electrotherapy and tissue repair. Sportex Med. 2006;29:7-13.

34. Draper DO, Castel JC, Castel D. Rate of temperature increase in human muscle during $1 \mathrm{MHz}$ and $3 \mathrm{MHz}$ continuous ultrasound. J Orthop Sports Phys Ther. 1995;22:142-50.

35. Qvist MH, Hoeck U, Kreilgaard B, Madsen F, Frokjaer S. Evaluation of Göttingen minipig skin for transdermal in vitro permeation studies. Eur J Pharm Sci. 2000:11:59-68.

36. Achterberg VF, Buscemi L, Diekmann H, Smith-Clerc J, Schwengler H, Meister JJ, Hinz B. The nano-scale mechanical properties of the extracellular matrix regulate dermal fibroblast function. J Invest Dermatol. 2014;134: 1862-72.

37. Pawlaczyk M, Lelonkiewicz M, Wieczorowski M. Age-dependent biomechanical properties of the skin. Postepy Dermatol Alergol. 2013;30:302.

38. Hendriks FM, Brokken D, Van Eemeren J, Oomens CWJ, Baaijens FPT, Horsten JBAM. A numerical-experimental method to characterize the non-linear mechanical behaviour of human skin. Skin Res Technol. 2003;9:274-83.

39. Boyer $\mathrm{G}$, Laquièze L, Le Bot $\mathrm{A}$, Laquièze $\mathrm{S}$, Zahouani H. Dynamic indentation on human skin in vivo: ageing effects. Skin Res Technol. 2009;15(1):55-67.

40. Cua AB, Wilhelm KP, Maibach HI. Elastic properties of human skin: relation to age, sex, and anatomical region. Arch Dermatol Res. 1990;282:283-8.

41. World Health Organization. Physical status: the use of and interpretation of anthropometry, Report of a WHO Expert Committee. 1995.

42. Ishikawa T, Ishikawa O, Miyachi Y. Measurement of skin elastic properties with a new suction device (I): relationship to age, sex and the degree of obesity in normal individuals. J Dermatol. 1995;22:713-7.

43. Draaijers J, Botman Y, Tempelman F, Kreis R, Middelkoop E, Van Zuijlen PPM. Skin elasticity meter or subjective evaluation in scars: a reliability assessment. Burns. 2004;30:109-14.

44. Mimoun N, Razzouq N, Wolkenstein P, Moreno JC, Marty JP, Lantieri L, Paul M. Evaluation of skin viscoelasticity in type 1 neurofibromatosis patients. Skin Pharmacol Physiol. 2006;19:22-27.

45. Reed B, Ashikaga T. The effects of heating with ultrasound on knee joint displacement. J Orthop Sports Phys Ther. 1997;26:131-7.

46. Lehmann JF, Masock AJ, Warren CG, Koblanski JN. Effect of therapeutic temperatures on tendon extensibility. Arch Phys Med Rehabil. 1970;51:481.

47. Fong SSL, Hung LK, Cheng JCY. The cutometer and ultrasonography in the assessment of postburn hypertrophic scar-a preliminary study. Burns. 1997; 23:12-8.

48. Cicchi R, Kapsokalyvas D, De Giorgi V, Maio V, Van Wiechen A, Massi D, Pavone FS. Scoring of collagen organization in healthy and diseased human dermis by multiphoton microscopy. J Biophotonics. 2010;3:34-43.

\section{Submit your next manuscript to BioMed Central and we will help you at every step:}

- We accept pre-submission inquiries

- Our selector tool helps you to find the most relevant journal

- We provide round the clock customer support

- Convenient online submission

- Thorough peer review

- Inclusion in PubMed and all major indexing services

- Maximum visibility for your research

Submit your manuscript at www.biomedcentral.com/submit
Biomed Central 